\title{
PENGARUH TEKNIK ABDOMINAL LIFTING TERHADAP NYERI PERSALINAN KALA I FASE AKTIF DI PMB MARTINI, AM. KEB KABUPATEN ACEH UTARA
}

\author{
Liana \\ Universitas Bina Bangsa Getsempena, Program Studi Sarjana Kebidanan \\ Liasst87@gmail.com
}

\begin{abstract}
Labor pain begins to arise in the first stage of the latent phase and the intensity of the pain will increase even more in the active phase, in the latent phase the cervix dilates up to $3 \mathrm{~cm}$ which can last for 8 hours. This study aims to analyze the effect of the Abdominal Lifting Technique on Pain in the First Stage of the Active Phase of Labor. The research method uses a quasi-experimental approach. The population in this study were all mothers giving birth at PMB Martini, Amd.Keb as many as 112 peoples. The sampling method used in this study was consecutive sampling with a planned sample size of 68 respondents. Data analysis in this study used dependent t-test (paired t-test) analysis. The results of the Mean test in the Abdominal Lifting Technique group were Pretest 3.32 and post-test 2.44 , the median value of the pretest was 3.00 and the posttest was 2.00 and the minimum pretest was 2 , the maximum was 4 , the minimum posttest value was 2 , the maximum was 4 . The $Z$ value was 4,362 and the $p$ value was 0.000 . The results of this study indicate that there is a difference in pain scale before and after performing the Abdominal Lifting Technique. The $Z$ value is -4.362 and the $p$ value is 0.000. The conclusion of this study shows that Abdominal Lifting has a strong influence on reducing pain during the first stage of labor.
\end{abstract}

Keywords $\quad$ : Abdominal Lifting, Pain, First Stage Labor

\begin{abstract}
ABSTRAK
Nyeri persalinan mulai timbul pada kala I fase laten dan akan lebih meningkat lagi intensitas nyeri tersebut pada fase aktif, pada fase laten terjadi pembukaan serviks sampai $3 \mathrm{~cm}$ bisa berlangsung selama 8 jam. Terdapat beberapa cara yang dapat dilakukan untuk mengurangi rasa nyeri persalinan dan meningkatkan kenyamanan ibu saat bersalin khususnya secara nonfarmakologi seperti: terapi musik, aromaterapi, kompres hangat, latihan nafas dan massage (Teknik Abdominal Lifting). Penelitian ini memiliki tujuan untuk menganalisis Pengaruh Teknik Abdominal Lifting Terhadap Nyeri Pada Kala I Fase Aktif Persalinan. Metode penelitian menggunakan pendekatan quasi experiment. Populasi pada penelitian ini adalah semua ibu bersalin di PMB Martini, Amd.Keb sebanyak 112 orang. Metode pengambilan sample yang digunakan dalam penelitian ini adalah consecutive sampling dengan jumlah sample direncanakan adalah 68 responden. Analisis Data dalam penelitian ini menggunakan analisis dependent t-test (paired t-test). Hasil uji Mean pada kelompok Teknik Abdominal Lifting yaitu Pretest 3,32 dan post test 2.44, nilai median pretest 3.00 dan posttest 2.00 Dan minimal pretest 2 , maksimal 4, nilai minimal posttest 2 , maksimal 4 . Nilai $Z-4,362$ dan $p$ value 0,000 . Hasil penelitian ini menunjukkan bahwa adanya skala perbedaan nyeri sebelum dan sesudah melakukan Teknik Abdominal Lifting. Nilai $Z-4,362$ dan nilai $p$ value 0,000. Kesimpulan penelitian ini menunjukan bahwa Abdominal Lifting memiliki pengaruh yang kuat terhadap penurunan nyeri saat Kala I pada persalinan. dengan hasil uji Wilcoxon nilai $\mathrm{Z}-4.362$ dan $p$ value 0,000 .
\end{abstract}

Kata Kunci : Abdominal Lifting, Nyeri, Persalinan Kala I

\section{PENDAHULUAN}

Nyeri persalinan merupakan sebuah pengalaman subjektif dari pasien yang disebabkan oleh iskemik otot uterus, penarikan dan traksi dari ligament uterus, traksi ovarium, tuba fallopi dan distensi bagian bawah uterus, otot dasar panggul dan perineum. Nyeri persalinan mulai timbul pada kala I fase laten dan akan 
lebih meningkat lagi intensitas nyeri tersebut pada fase aktif, pada fase laten terjadi pembukaan serviks sampai $3 \mathrm{~cm}$ bisa berlangsung selama 8 jam (Ningsih \& Rahmawati, 2019).

Menurut World Health Organization WHO (2020), sebanyak 295.000 wanita di seluruh dunia kehilangan nyawa selama dan setelah kehamilan dan persalinan. Pada tahun 2017, negara Afrika dan Selatan Asia menyumbang sekitar $86 \%$ dari semua kematian di seluruh dunia. Angka Kematian Ibu (AKI) secara global (jumlah kematian ibu per 100.000 kelahiran hidup) diperkirakan 211 mewakili pengurangan $38 \%$ sejak tahun 2000.

Rata-rata angka kematian ibu secara global menurun 2,9\% setiap tahun antara tahun 2000 dan 2017. Jika laju dapat dipercepat untuk mencapai target SDGs (mengurangi Angka Kematian Ibu secara global menjadi kurang dari 70 per 100.000 kelahiran hidup), itu akan menyelamatkan nyawa setidaknya 100.0000 wanita.

Berdasarkan dari data yang bersumber dari dinas kesehatan kabupaten/kota diketahui Angka Kematian Ibu di Aceh lima tahun terakhir berfluktuasi, pada tahun 2019 mengalami kenaikan menjadi 172 per 100,000 kelahiran dengan jumlah kematian ibu sebanyak 157 kasus, tertinggi di kabupaten Aceh Utara sebanyak 25 kasus di ikuti Bireuen 16 kasus, terendah di Pidie Jaya sebanyak 1 kasus (DINKES Aceh, 2019).

Berdasarkan data di atas dapat disimpulakn bahwa Angka Kematian Ibu masih sangatlah tinggi, melahirkan menjadi salah satu penyebab utama dari menigkatnya kematian perempuan pada usia subur. Gangguan pada kontraksi uterus atau inersia uteri merupakan dampak dari nyeri persalinan (Chotimah, 2020).

Terdapat beberapa cara yang dapat dilakukan untuk mengurangi rasa nyeri persalinan dan meningkatkan kenyamanan ibu saat bersalin khususnya secara nonfarmakologi seperti: massage (pemijatan), terapi musik, aromaterapi, kompres hangat, latihan nafas (Breathing Exercise), dan latihan birthball (Solehati, $\mathrm{dkk}, 2018$ ).

Hasil studi pendahuluan berupa wawancara pada 10 (100\%) responden mengenai massage (pemijatan) saat proses persalinan di PMB Martini, Am.Keb Kabupaten Aceh Utara. Diperoleh 7 (70\%) dari $10(100 \%)$ responden mengatakan tidak mengetahui apa itu teknik Kneading dan Abdominal Lifting, juga tidak pernah malakukan massage (pemijatan) selama proses persalinan. Sedangkan $3(30 \%)$ dari $10(100 \%)$ responden mengatakan pernah malakukan massge (pemijatan) selama proses persalinan guna untuk mengurangi rasa nyeri pada persalinan.

Teknik Abdominal Lifting menjadi salah satu alternatif pilihan untuk mengurangi rasa persalinan Kala I disebabkan sudah menjadi kebiasaan ibu yang akan bersalin, atau dengan kata lain Abdominal Lifting adalah "kusuk" atau dalam bahasa Indonesia adalah pijat/memijat. Sehingga tidak terjadi penolakan secara jelas jika seorang bidan melakukan peminjatan atau mengajari keluarga untuk melakukan pemijatan.

Penelitian ini memiliki tujuan untuk menganalisis Pengaruh Teknik Abdominal Lifting Terhadap Nyeri Pada Kala I Fase Aktif Persalinan Di PMB Martini, Am.Keb Kabupaten Aceh Utara

\section{METODE}

Penelitian yang digunakan adalah kuantitatif atau quantitative design dengan pendekatan quasi experiment. Penelitian ini dilakukan di PMB Martini, Am.Keb di Lhoksukon Kabupaten Aceh Utara pada 1 Juni s/d 6 Juli 2021. Populasi pada penelitian ini adalah semua ibu bersalin di PMB Martini, Am.Keb sebanyak 112 orang ibu bersalin terhitung mulai dari bulan Januari sampai bulan Mei tahun 2021.

Metode pengambilan sample yang digunakan dalam penelitian ini adalah 
consecutive sampling dengan jumlah sample direncanakan adalah 68 responden. Kriteria inklusi dalam penelitian ini adalah, ibu bersedia untuk diberikan Terapi Teknik Abdomial Lifting, Ibu bersalin dengan kala I fase aktif $4-8 \mathrm{~cm}$, Semua ibu bersalin, Tidak memiliki riwayat penyakit menahun selama kehamilan.

Analisis Data dalam penelitian ini menggunakan analisis dependent t-test (paired t-test). Sedangkan untuk Uji normalitas data dan uji homogenitas data penelitian yang digunakan pada penelitian ini adalah Kolmogorov-Smirnov.

\section{HASIL}

Praktik Mandiri Bidan (PMB) Martini, Am.Keb adalah salah satu PMB yang berada di Kabupaten Aceh Utara dan berada di Kecamatan Lhoksukon \pm 243.00 $\mathrm{km}^{2}$.

Tabel 1. Distribusi Frekuensi Data Demografi Responden

\begin{tabular}{clcc}
\hline \multirow{2}{*}{ No } & \multicolumn{1}{c}{$\begin{array}{c}\text { Umur } \\
\text { Responden }\end{array}$} & \multicolumn{2}{c}{$\begin{array}{c}\text { Teknik Abdominal } \\
\text { Lifting }\end{array}$} \\
\cline { 3 - 4 } & \multicolumn{1}{c}{$\boldsymbol{f}$} & \% \\
\hline 1 & Umur & & \\
& $<20$ Tahun & 2 & 5.9 \\
& 20-30 Tahun & 20 & 58.8 \\
& $>30$ Tahun & 12 & 35.3 \\
\hline 2 & Pekerjaan & & \\
& Bekerja & 14 & 41.1 \\
& Tidak bekerja & 20 & 58.8 \\
\hline 3 & Pendidikan & & \\
& Tinggi & 12 & 35.3 \\
& Menengah & 17 & 50.0 \\
& Dasar & 5 & 14.7 \\
\hline
\end{tabular}

(Sumber : Data Diolah Tahun 2021)

Berdasarkan tabel diatas, usia ibu yang hamil atau akan melahirkan pada rentang usia produktif sebesar 58,8\%. Sedangkan untuk status pendidikan dala rentang pendidikan menengah yaitu SMA sederajat sebesar $50 \%$.

Dari Tabel 2 dapat dilihat bahwa skala nyeri persalinan sebelum diberikan tindakan skala nyeri persalinan sesudah diberikan Teknik Abdominal Lifting mayoritas responden mengalami nyeri dengan skala $1-3$ sebanyak 24 responden (70.6\%). Dan tidak ada responden yang mengalami nyeri dengan skala 0 dan 7-10.

Tabel 2. Distribusi frekuensi Skala Nyeri Ibu Bersalin Sebelum dan Sesudah Diberikan Teknik Abdominal Lifting Di PMB Martini, Amd. Keb Kebupaten Aceh Utara

\begin{tabular}{ccccc}
\hline \multirow{2}{*}{$\begin{array}{c}\text { Nyeri } \\
\text { Persalainan }\end{array}$} & \multicolumn{4}{c}{ Taknik Abdominal Lifting } \\
\cline { 2 - 5 } & \multicolumn{2}{c}{ Sebelum } & \multicolumn{2}{c}{ Sesudah } \\
\cline { 2 - 5 } & $\boldsymbol{f}$ & $\%$ & $\boldsymbol{f}$ & $\%$ \\
\hline 0 & 0 & 0 & 0 & 0 \\
\hline $1-3$ & 1 & 2.9 & 21 & 61.8 \\
\hline $4-6$ & 21 & 61.8 & 11 & 32.4 \\
\hline $7-10$ & 12 & 35.3 & 2 & 5.9 \\
\hline Jumlah & 34 & 100 & 34 & 100 \\
\hline (Sumber : Data Diolah Tahun 2021) \\
\end{tabular}

Tabel 3. Analisa Bivariat Uji Wilcoxon Teknik Abdominal Lifting

\begin{tabular}{lccccc}
\hline & N & $\begin{array}{c}\text { Mea } \\
\mathbf{n}\end{array}$ & $\begin{array}{c}\text { Medi } \\
\mathbf{a}\end{array}$ & $\mathbf{Z}$ & $\begin{array}{c}\boldsymbol{P} \\
\text { Value }\end{array}$ \\
\cline { 1 - 4 } Teknik & & & & & \\
$\begin{array}{l}\text { Abdomi } \\
\text { nal }\end{array}$ & & & & & \\
Lifting & & & & & \\
\cline { 1 - 2 } Pre & 34 & 3,32 & 3,00 & & 0,000 \\
& & & & \\
Post & 34 & 2,24 & 2,00 & &
\end{tabular}

(Sumber : Data Primer Diolah Tahun 2021)

Mean pada kelompok Teknik Abdominal Lifting yaitu Pretest 3,32 dan post test 2.44, nilai median pretest 3.00 dan posttest 2.00 dan minimal pretest 2 , maksimal 4, nilai minimal posttest 2 , maksimal 4. Nilai $\mathrm{Z}-4,362$ dan $p$ value 0,000 . Hasil penelitian ini menunjukkan bahwa adanya skala perbedaan nyeri sebelum dan sesudah melakukan Teknik Abdominal Lifting. Nilai Z -4,362 dan nilai $p$ value 0,000

\section{PEMBAHASAN}

Dari hasil penelitian yang dilakukan peneliti skala nyeri persalinan sebelum diberikan Teknik Abdominal Lifting 
mayoritas responden mengalami nyeri dengan skala $4-6$ sebanyak 21 responden $(61.8 \%)$ dan tidak ada responden yang mengalami nyeri dengan skala 0 .

Menurut hasil penelitian yang dilakukan oleh Malawat (2020), menunjukkan sebelum diberikan teknik abdominal lilfting pada ibu bersalin mayoritas merasakan nyeri sedang sebanyak 6 responden $(49,98 \%)$, dan 2 responden $(16.66 \%)$ merasakan nyeri ringan, dan 4 responden $(33.32 \%)$ mengalami nyeri berat.

Rasa aman dan nyaman Menurut Potter \& Perry (2006) yang dikutip dalam buku (Iqbal Mubarak,Indrawati, \& Susanto, 2015) rasa nyaman merupakan merupakan keadaan terpenuhinya kebutuhan dasar manusia yaitu kebutuhan ketentraman (kepuasan yang dapat meningkatkan penampilan sehari-hari), kelegaan (kebutuhan yang telah terpenuhi), dan transenden.

Menurut Orshan (2008), nyeri persalinan ditandai dengan adanya kontraksi rahim, kontraksi sebenarnya telah terjadi pada minggu ke-30 kehamilan yang disebut kontraksi braxton hicks akibat perubahan-perubahan dari hormon estrogen dan progesteron tetapi sifatnya tidak teratur, tidak nyeri dan kekuatan kontraksinya sebesar $5 \mathrm{mmHg}$, dan kekuatan kontraksi braxton hicks ini akan menjadi kekuatan his dalam persalinan dan sifatnya teratur.

Berdasarkan hasil penelitian yang dilakukan peneliti skala nyeri persalinan sebelum diberikan Teknik Abdominal Lifting mayoritas responden mengalami nyeri dengan skala 4-6 sebanyak 21 responden $(61.8 \%)$ dan tidak ada responden yang mengalami nyeri dengan skala 0.

Hasil penelitian menunjukkan penurunan rasa nyeri pada ibu bersalin berkaitan kuat dengan intevensi yang dilakukan yaitu pijatan Abdominal Lifting. Pemijatan yang dilakukan membuat seorang ibu merasaka aman, nyaman serta diperdulikan. Hal tersebut dapat meningkatkan kekuatan ibu saat akan melakukan persalinan.

Menurut penelitian Malawat (2020), terlihat standar deviasi rasa nyeri persalinan antara sebelum dan sesudah pemberian tindakan metode Abdominal Lifting. Perbedaan ini diuji dengan uji $\mathrm{t}$ berpasangan didapatkan nilai $\mathrm{t}-$ hitung $>\mathrm{t}$ tabel $(6952>1812)$ berarti ada pengaruh yang signifikan antara sebelum dilakukan tindakan metode abdominal lifting dan sesudah dilakukan tindakan metode Abdominal Lifting. Dengan diberikannya pemberian tindakan metode abdominal lifting berarti ada pengaruh terhadap penguranagan intensitas nyeri persalianan. Yang mana metode Abdominal Lifting dapat diberikan kepada ibu inpartu kala I fase aktif disaat ada kontraksi, lama pemberian Abdominal Lifting dalam penelitian ini diberikan 2-3 kali permenit dan berlagsung selama 50-60 detik dalam pembukaan serviks $4 \mathrm{~cm}$ sampai pembukaan serviks lengkap $10 \mathrm{~cm}$.

Meredakan ataupun menghilangkan rasa nyeri secara non farmakologi merupakan hal yang tidak instan dan mudah, diperlukan teknik, lokasi, waktu serta keterampilan yang mumpuni. Kebutuhan dasar seorang manusia menurut Abraham maslow salah satunya adalah rasa aman dan nyaman, maka teknik Abdominal Lifting yang dilakukan oleh peneliti mengutamakan rasa nyaman dan aman baru selanjutnya teknik, lokasi, waktu dan keterampilan.

\section{KESIMPULAN}

Hasil penelitian ini menunjukkan bahwa Abdominal Lifting memiliki pengaruh yang kuat terhadap penurunan nyeri saat Kala I pada persalinan. dengan hasil uji Wilcoxon nilai $\mathrm{Z}-4.362$ dan $p$ value 0,000 yang berarti terdapat perbedaan sebelum dann sesudah melakukan Teknik Abdominal Lifting di PMB Martini, Am.Keb. 


\section{UCAPAN TERIMAKASIH}

Bersyukur atas Tuhan Yang Maha Esa, yang telah memberikan rahmat serda hidayahnya kepada peneliti untuk dapat menyelesaikan penelitian ini dalam kondisi baik

\section{DAFTAR PUSTAKA}

Alam, S, H. (2020). Upaya Mengurangi Nyeri Persalinan Dengan Metode Akupresur. Bandung : CV Media Sains Indonesia.

Brown, A. (2019). The Swedish Massage : Full Body Therapy. UK : Inspiration.

Chotimah, S, H, dkk. (2020). Perbedaan Teknik Pernafasan Dan Teknik Kneading Terhadap Intensitas Nyeri Pada Persalinan Kala I Fase Aktif Di Wilayah Walantaka Kota Serang Tahun 2020. Jurnal Ilmiah Kesehatan Dan Kebidanan. Vol.IX. No.2, Juni 2020. Jakarta : Mitra Ria Husada.

Data Dinkes Aceh. (2019). Profil Kesehatan Aceh 2019.

Data Kemenkes RI. (2020). Profil Kesehatan Indonesia Tahun 2019. Jakarta : Kementrian Kesehatan RI.

Data PMB Martini, Am. Keb. (2020). Data Awal Ibu Bersalin. Kabupaten Aceh Utara.

Data WHO. (2020). World Health Statistics 2020 : Monitoring Health For The SDGs (Sustainable Development Goals).

Felaili, S, E, \& Machmudah. (2017). Teknik Kneading Menurunkan Tingkat Nyeri Persalinan Kala I Pada Ibu Bersalin Di Kabupaten Semarang. Jurnal Kebidanan. Vol. IX, No. 01, Juni 2017. Semarang : Universitas Muhammadiyah Semarang.

Fitriahadi, E, \& Utami, I. (2020). Buku Ajar Asuhan Persalinan \& Managemen Nyeri Persalinan. Yogyakarta : Unisa.
Lanina, G, dkk. (2020). Pengaruh Kombinasi Teknik Kneading Dan Relaksasi Nafas Dalam Terhadap Intensitas Nyeri Kala I Persalinan Di PMB Rabiah Abuhasan Palembang. JAKHKJ. Vol. 6, No. 2, 2020. Palembang : Fakultas Ilmu Kesehatan, Universitas Nasional.

Malawat, R. (2020). Pengaruh Metode Abdominal Lifting Terhadap Intensitas Nyeri Ibu Inpartu Kala I Fase Aktif Di Rumah Sakit Tkt II Dr. J. Latumeten Ambon. Volume 5 Number 1, March 2020. Maluku : Poltekkes Kemenkes Maluku.

Ningsih, M, P, N, \& Rahmawati, L. (2019). Efektifitas Teknik Counter Presure Dan Abdominal Lifting Terhadap Pengurangan Rasa Nyeri Pada Ibu Bersalin Kala I Fase Aktif Di PMB Kota Padang. Medikes (Media Kesehatan), Volume 6, Nomor 2, 2020. Palembang : Fakultas Ilmu Kesehatan, Universitas Nasional.

Notoadmodjo. (2014). Metodologi Penelitian Kesehatan. Jakarta : Rineka Cipta.

Rejeki, S. (2018). Buku Ajar Manajemen Nyeri Dalam Proses Persalinan (Non Farmaka). Semarang : Unimus Press.

Solehati, dkk. (2018). Terapi Nonfarmakologi Nyeri Pada Persalinan. Jurnal Kebidanan. Padjajaran : Faculty Of Nursing Universitas Padjajaran. 